\title{
VIRTUDE E SABEDORIA: UMA REFLEXÃO ÉTICA PARA A SOCIEDADE DO CONHECIMENTO
}

\author{
Alvaro Martins Fernandes Junior ${ }^{1}$, Siderly do Carmo Dahle de Almeida ${ }^{2}$, Marivaldo da Silva Oliveira ${ }^{3}$, \\ Amanda Louise Bruzamolin ${ }^{4}$ \\ ${ }^{1}$ Doutorando em Educação e Currículo na Pontifícia Universidade Católica - PUC, SP. Docente na Escola Superior \\ Gestão Pública, Política, Jurídica e Segurança do Centro Universitário Internacional - UNINTER. \\ ${ }^{2}$ Doutora em Educação e Currículo pela Pontifícia Universidade Católica - PUC, SP. Coordenadora e docente do \\ Programa de Mestrado Profissional em Educação e Novas Tecnologias do Centro Universitário Internacional - \\ UNINTER. \\ ${ }^{3}$ Mestre em Gestão do Conhecimento nas Organizações pelo Centro Universitário de Maringá - UNICESUMAR, PR. \\ Coordenador do Curso de Medicina Veterinária da FATECIE. \\ ${ }^{4}$ Especialista em Vigilância Sanitária pelo Centro Universitário Internacional - UNINTER. Médica Veterinária Visitadora \\ da Drogavet - Unidade Maringá.
}

\section{RESUMO}

Este texto tem por objetivo traçar uma análise da sociedade do conhecimento que parece não estar conseguindo atender aos preceitos de sua existência, pois esperava-se que com maior acesso ao conhecimento a humanidade pudesse diminuir as desigualdades, aumentar a sapiência e a virtuosidade. Porém, o que se observa são índices grandes de desigualdade e bastante falta de ética daqueles que poderiam fazer mais pelos que possuem menos - menos poder, menos riquezas, menos acesso ao conhecimento. $O$ texto sugere que é pela educação que novos caminhos éticos poderão ser traçados para que a sociedade possa se desenvolver, melhorando a qualidade de vida dos menos favorecidos e, consequentemente, buscando atingir aos princípios da sociedade do conhecimento.

Palavras-chave: Ética. Virtude. Sabedoria. Educação. Sociedade do conhecimento.

\section{VIRTUE AND WISDOM: AN ETHICAL REFLECTION FOR THE KNOWLEDGE SOCIETY}

\begin{abstract}
This text aims to trace an analysis of the knowledge society that seems to be unable to meet the precepts of its existence since it was hoped that with greater access to knowledge, humanity could reduce inequalities, increase wisdom and virtuosity. But what is observed are a large indices of inequality and a lack of ethics of those who could do more for those who have less - less power, less wealth, less access to knowledge. The text suggests that it is through education that new ethical paths can be traced so that society can develop, improving the quality of life of the disadvantaged and, consequently, seeking to reach the principles of the knowledge society.
\end{abstract}

Keywords: Ethics. Virtue. Wisdom. Education. Knowledge Society.

VIRTUD Y SABIDURÍA: UNA REFLEXIÓN ÉTICA PARA LA SOCIEDAD DEL CONOCIMIENTO

\section{RESUMEN}

Este texto tiene por objetivo trazar un análisis de la sociedad del conocimiento que parece no estar logrando atender a los preceptos de su existencia, pues se esperaba que con mayor acceso al conocimiento la humanidad pudiera disminuir las desigualdades, aumentar la sabiduría y la virtuosidad. Pero lo que se observa son índices grandes de desigualdad y bastante falta de ética de aquellos que podrían hacer más por los que poseen menos - menos poder, menos riquezas, menos acceso al conocimiento. El texto sugiere que 
es por la educación que nuevos caminos éticos pueden ser trazados para que la sociedad pueda desarrollarse mejorando la calidad de vida de los menos favorecidos y consecuentemente buscando alcanzar los principios de la sociedad del conocimiento.

Palabras clave: Ética. Virtud. Sabiduría. Educación. Sociedad del conocimiento

\section{INTRODUÇÃO}

Sempre que estiver em dúvida, ou quando o ego crescer muito em você, faça o seguinte [...] lembre-se do rosto do homem mais pobre e desvalido que tenha visto, e pergunte-se se o passo que você está pensando em dar será de alguma utilidade para ele. Esse passo fará com que ele ganhe alguma coisa? Devolver-lhe-á o controle sobre sua vida e seu destino? Em outras palavras, levará swaraj ${ }^{1}$ aos milhões de famintos e aos espiritualmente carentes? Você verá então sua dúvida e seu ego se dissolverem" (Mahatma Gandhi')

Este texto inicia com a epígrafe de Gandhi lembrando que àqueles que possuem o acesso à Educação devem trabalhar de forma virtuosa e com sabedoria para que todos tenham acesso a mesma. Na contemporaneidade isso requer uma reflexão ética, e, nesse sentido, se revela a importância de utilizar o conhecimento como forma de propiciar melhores condições para aqueles que não o possuem. Analisando as ideias do filósofo Sócrates, deve-se depreender que, para ele, o conhecimento equivale a busca pela felicidade, considerando-se que "conhecer a si mesmo" priva o homem de cometer ignorâncias. Nesta mesma perspectiva, no auge do Renascimento, surge Kant que, em sua filosofia, abordava a importância da educação para que o homem não fosse bárbaro.

Contemporâneo de Kant, o filósofo moderno Francis Bacon pretendia uma grande renovação: reformar as ciências de tal modo que

\footnotetext{
${ }^{1}$ Conceito de Mahatma Gandhi que se referia a independência indiana dos britânicos, auto governança.

${ }^{2}$ Fala transcrita do livro LELYVELD, Joseph. Great soul: Mahatma Gandhi and his struggle with India. New York: Alfred A. Knopf, 2011.
}

fosse possível passar de um saber especulativo para um saber ativo, e para isso planejou uma grande obra intitulada de Instauratio Magna (a grande instauração). Para o filósofo em questão, as ciências deveriam transformar a vida do homem e trabalhar a seu favor.

Bacon admitia que a evolução de conhecimentos e de técnicas, assim como as reformas sociopolíticas e o progresso das ciências e da própria filosofia, oportunizariam uma ampla reforma do conhecimento, o que poderia ser ainda uma reforma importante na vida humana. (BACON, 1999, p. 20). Por meio de uma reforma nas ciências e no conhecimento o homem chegaria a novas explicações e teorias. Em sua obra Novum Organum, no IX aforismo ele afirma, "a verdadeira causa e raiz de todos os males que afetam as ciências é uma única: enquanto admiramos e exaltamos de modo falso os poderes da mente humana, não lhe buscamos auxílios adequados", ou seja, ao invés de especular sobre a natureza, o homem deveria domina-la. Considerando este contexto, a filosofia deveria ser algo prático, em que saber se traduz em poder.

Mais contemporaneamente, e menos empolgado com as perspectivas do conhecimento humano, nos deparamos com a fala de Harari (2016) que salienta que embora estejamos inseridos na sociedade do conhecimento, e ainda que pestes tenham sido exterminadas, a paz reine entre a maioria dos povos e o número de pessoas felizes tenha aumentado, o ser humano ainda busca mais: ele deseja a sua transformação de Homo Sapiens para Homo Deus, afinal, "a agenda dos que vivem em palácios é diferente da dos que vivem em barracos e não é provável que isso vá mudar no século XXI" (HARARI, 2016, p. 64).

De Masi (2014, p. 17) faz uma constatação óbvia "[...] nunca como agora o planeta foi habitado por uma massa tão grande de matéria cinzenta escolarizada. Somos o maior cérebro coletivo que jamais existiu, que continuará crescendo nas próximas décadas". Então, é o momento de passar a refletir em 
virtude de causas mais nobres, em favor daqueles que nunca foram o centro das discussões.

Considerando os teóricos em questão, pretende-se neste estudo, por meio de uma pesquisa bibliográfica, delinear uma análise da sociedade do conhecimento que parece não estar conseguindo atender aos preceitos de sua existência, pois esperava-se que com maior acesso ao conhecimento a humanidade pudesse diminuir as desigualdades, aumentar a sapiência e a virtuosidade.

\section{ATUAL CONJUNTURA}

$\mathrm{Na}$ contemporaneidade, vemo-nos forçados a reconhecer que o que está em crise não é a realidade, mas sim "[...] a nossa maneira de interpretá-la, os nossos modelos: uma vez que as categorias mentais oriundas da época industrial já não são capazes de explicar o presente, acabamos sendo induzidos a desconfiar do futuro" (DE MASI, 2014, p. 17).

Contemporaneamente, se vive em um estado de crise constante (BAUMAN; BORDONI, 2016), oriundo de uma também constante inversão de valores em que a sociedade se vê: a "sociedade sem conhecimento" pregando pelo interesse dos abastados ao invés de encontrar meios de prover a igualdade, e consequentemente $\mathrm{o}$ desenvolvimento. $\mathrm{O}$ filósofo Enrique Dussel (2000) é enfático ao afirmar que os discursos éticos vigentes não consideram a realidade mundial, onde seus formuladores não realizam um juízo ético do sistema histórico-social no qual estão imersos e consideram apenas uma realidade utópica.

Tomando as palavras de Bauman (2001), a realidade que está posta é líquida, não conserva a forma, está sempre aberta a mudança, não se fixa no espaço e nem no tempo, é leve e fluída.

\footnotetext{
o que torna 'líquida' a modernidade, e assim justifica a escolha do nome, é sua 'modernização' compulsiva e obsessiva, capaz de impulsionar e intensificar a si mesma, em consequência do que, como ocorre com os líquidos, nenhuma das formas consecutivas de vida social é capaz de manter seu aspecto por muito tempo (BAUMAN, 2001, p. 16)
}

Assim, dissolve-se o que é sólido e, ao contrário do que acontecia em outros tempos, o que foi dissolvido não deve ser substituído por outra forma sólida ou permanente, pois nada deve resistir a liquefação. Tudo é inconstante na modernidade líquida, modelado de modo a se ajustar as liberdades de escolha de cada indivíduo, aceitando, com imparcialidade, todos os gostos, todas as opiniões, todas as formas de viver, afastando padrões mais rígidos. Por outro lado, o indiano Capra (2006, p. 18) assevera que,

Quando estruturas sociais e padrões de comportamento tornamse tão rígidos que a sociedade não pode mais adaptar-se a situações cambiantes, ela é incapaz de levar avante o processo criativo de evolução cultural. Entra em colapso e, finalmente, desintegrase. Enquanto as civilizações em crescimento exibem uma variedade e uma versatilidade sem limites, as que estão em processo de desintegração mostram uniformidade e ausência de inventividade. A perda de flexibilidade numa sociedade em desintegração é acompanhada de uma perda geral de harmonia entre seus elementos, o que inevitavelmente leva ao desencadeamento de discórdias e à ruptura social.

A própria contextualização da sociedade demonstrada pelos autores supracitados é uma prova das incertezas que encabeçam e definem a contemporaneidade, pois o que Bauman chama de líquido pela fluidez e leveza, Capra chama de rígido pelo fato de não serem facilmente adaptáveis e flexíveis, nomenclaturas paradoxais para o mesmo tempo e que intentam descrever a mesma sociedade.

\subsection{Um debate ético}

$O$ termo ética vem do grego ethos que possui como significado "uso, costume, modo de comportar-se, caráter" (VENDEMIATI, 2008, p. 
35) e é entendida como "a ciência que indica aquilo que o homem deve fazer para ser bom, isto é, digno da própria humanidade" (VENDEMIATI, 2008, p. 19). Em suma, ética é a ciência daquilo que o homem deve ser, porque a vida moral não consiste somente no fazer, em sentido estreito, mas em orientar toda a nossa atividade em um determinado modo, rumo a um ideal humano. Resumindo: buscar um sentido do humano existir ou, em forma de pergunta, "como devemos ser para realizar plenamente a nossa personalidade humana?" (VENDEMIATI, 2008, p. 20).

Se no grego ética vem de éthos, no latim ela corresponde ao termo mos, moris. Partindo desta categorização não faremos distinção entre moral e ética, consideremos os termos como sinônimos (VENDEMIATI, 2008). A moral exprime uma normatividade categórica, "[...] você deve comportar-se desta ou daquela maneira não somente para obter um escopo particular, mas para realizar o escopo de existência humana enquanto tal [...], prescreve como se deva comportar para ser bons enquanto homens: para ser dignos da própria humanidade" (VENDIAMATI, 2008, p. 42).

Cabe ressaltar que a ética não se reduz ao estabelecimento e discussões de normas, prescrições e proibições. Ela se interessa pela reflexão dos fundamentos das normas, que consistem em indicações "[...] com as quais conseguimos guiar a nossa vida, governar a nossa existência em modo de desenvolver a nossa personalidade em relação com os outros homens, com Deus e com o mundo" (VENDEMIATI, 2008, p. 42).

O filosofo Dussel (2000, p. 131-132, grifos no original) coloca que

[...] a vida humana é o modo de realidade do sujeito ético, que dá o conteúdo a todas as suas ações, que determina a ordem racional e também o nível das necessidades, pulsões e desejos, que constitui o marco dentro do qual se fixam os fins[...] a vida humana impõe limites, fundamenta normativamente uma ordem, tem exigências próprias. Impõe também conteúdos: há necessidade de alimentos, casa, segurança, liberdade e soberania, valores e identidade cultural, plenitude espiritual. A vida humana é o modo de realidade do ser ético.

Então, ética relaciona-se com o desenvolvimento da nossa personalidade ao se constituir como fundamento da moralidade, e a plena realização deste desenvolvimento constitui-se como felicidade verdadeira, e as modalidades em que este se realiza, são as virtudes.

Por virtude entende-se "[...] um habitus que desenvolve a nossa personalidade em modo digno do ser humano" (VENDEMIATI, 2008, p. 97), e em relação ao agir virtuosamente. A virtude se mostra a nós como a atitude ou a disposição estável a um comportamento autenticamente livre, ou seja, agir em modo correspondente às exigências da razão, comandando com a vontade a própria conduta (VENDEMIATI, 2008, p. 97)

Portanto, ser virtuoso é conhecer o bem e escolher por realiza-lo, virtude motoriza a vida moral, é um modo de ser, é governo da razão, equilíbrio, harmonia e, tomando as palavras de Santo Agostinho, "[...] a virtude é uma boa qualidade espiritual, graças à qual se vive retamente e da qual ninguém pode abusar [...]", e "[...] sabedoria é o habitus que orienta estavelmente a razão ao verdadeiro bem, conferindo-lhe a atitude de escolher os meios oportunos e concretamente disponíveis na situação, para atingir o fim mesmo" (VENDEMIATI, 2008, p. 115). Entende-se por sabedoria a virtude da prudência, que nos guia a consumação plena do sentido de viver (VENDEMIATI, 2008).

Sendo o conhecimento da realidade a primazia da sabedoria para que o bem se efetive, e essa sabedoria é um comando da razão prática que diz que algo é bom e deve ser feito, torna-se passível entender que ela nos faz conhecer os meios que devemos querer e usar (VENDEMIATI, 2008).

Betini (2017, p. 279), sobre o papel da sociedade e do Estado quanto a formulação de políticas educacionais, evidencia uma importante questão:

Qual o papel da sociedade e do Estado na formulação das políticas educacionais, suas tendências e 


\begin{abstract}
direcionamento que nem sempre atendem totalmente às aspirações das camadas menos favorecidas da sociedade. $\mathrm{Na}$ verdade, a educação oferecida a essa parcela da população atende aos interesses das forças hegemônicas, visando à educação para o consenso. O Estado não deixa de olhar para as classes populares, porém sempre como dominadas. Compete ao Estado capitalista a busca do equilíbrio, instável é verdade, entre dominados e dominantes.
\end{abstract}

Então, cabe aqui uma dúvida: por onde começar a reflexão ética? Por meio da promoção dialética que a Educação provê, que é essencial para que as premissas da sociedade do conhecimento se consolidem, para que o conhecimento adquirido seja útil para os interesses da maioria, especialmente àqueles que são menos favorecidos

Os avanços tecnológicos podem exacerbar a desigualdade. Pelo menos inicialmente, os detentores de poder e voz estão em melhor posição para adquirir e adaptar novas tecnologias, fazendo com que as prioridades de atividades de pesquisa e desenvolvimento sejam canalizadas para satisfazer suas necessidades [...] Somente $1 \%$ dos novos medicamentos

comercializados entre 1975 e 1996 foi desenvolvido pra o tratamento de doenças tropicais. Dez anos depois, e a despeito de alguns esforços filantrópicos, essa disparidade permanece: somente $\quad 10 \%$ do orçamento global para pesquisas na área da saúde (US\$ 50 a 60 bilhões) são gastos com doenças que afetam $90 \%$ da população do mundo. (GREEN, 2009, p. 60)

A Educação provê àqueles que possuem acesso a ela o direito de querer mudar uma situação de descontentamento. É possível inferir que é apenas por meio dela que as pessoas compreenderão em que condições vivem e como estas podem ser alteradas para melhor, sendo essa a primeira função da educação, a de abrir os olhos da sociedade. Essa mesma educação ainda é o que provê ferramentas para o combate e a busca pelo desenvolvimento, em que quadros mentais e atitudes não podem ser transformados e consentir o processo evolutivo imposto pelo desenvolvimento sem que existam as bases humanas fornecidas pela educação.

"A educação é crucial para romper o ciclo da pobreza [...]" (GREEN, 2009, p. 45) e quando se fala na relação ética-educação é essencial pensar no "lado econômico" da relação, mesmo que não seja o escopo do presente estudo, não há como pensar em "se educar" se não há condições mínimas de sobrevivência no país. Inicialmente, é preciso atender as necessidades básicas humanas, para depois pensar em Educação. É conforme se aprende que, quanto mais se compartilha mais se aprende, pois, ao compartilhar conhecimento permite-se a conexão com indivíduos de ideias contrárias (ou não) as nossas, e que desta maneira, podem contribuir para a construção de uma inteligência coletiva (LEVY, 2003). Esta por sua vez, é fundamental para uma sociedade que se alimenta e consome conhecimento (GREEN, 2009).

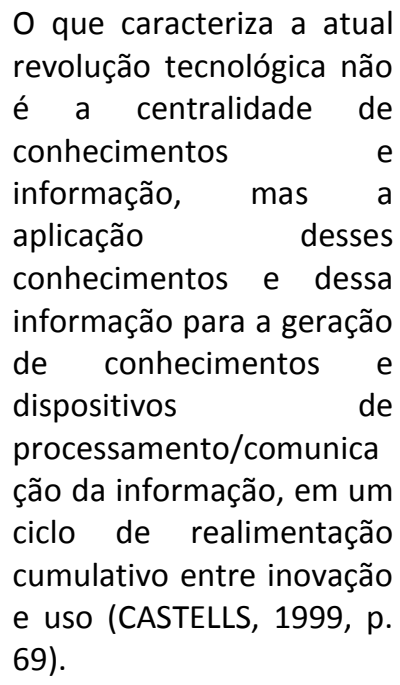

Considerando a conjuntura situada até aqui e a necessidade de prover soluções para a 
mesma, emerge a necessidade de se tecer uma reflexão ética para essa sociedade do conhecimento, e ainda, sendo o conhecimento sinônimo de poder; virtude, a disposição em corresponder as exigências da razão comandando a conduta pela própria vontade; e a sabedoria, a prudência que nos guia a consumação do pleno sentido de viver, é pela educação que se deve iniciar essa discussão.

\section{A EDUCAÇÃO COMO ESSÊNCIA DO DEBATE ÉTICO}

Sendo a Educação o repousar do saber, é por meio dela que se empoderam indivíduos e torna-se possível o seu desenvolvimento. Ressalta-se que a contemporaneidade perpassa pelo que o teólogo Leonardo Boff chama de crise social:

[...] que se prende à forma como as sociedade modernas se organizaram no acesso, na produção e na distribuição dos bens da natureza e da cultura. Essa forma profundamente desigual, porque privilegia as minorias que detêm o ter, o poder e o saber sobre as grandes maiorias que vivem do trabalho [...] Os laços de solidariedade e de cooperação não são axiais, mas o são o desempenho individual e a competitividade, criadores permanentes de apartação social com milhões de marginalizados, de excluídos e de vítimas. (BOFF, 2003, p. 15).

Considerando a crise social, pode-se entender o atual quadro de liquidez cunhado pelo sociólogo polonês Zygmunt Bauman que afirma que "precisamos desesperadamente de um novo quadro que acomode e organize nossas experiências" (2011, p. 7), e se faz emergir a necessidade de discutir o uso do conhecimento apropriado pelo homem de forma virtuosa e sábia, o que nos leva à uma reflexão ética.

Determinar qual fator é o primeiro de um ciclo de desenvolvimento é uma tarefa de alta complexidade, visto que não há educação sem saneamento, e a recíproca também é verdadeira. Assim como é verdadeiro que não são apenas esses dois fatores que corroboram para o desenvolvimento de uma Nação, porém, o presente trabalho não possui como intuito elencar todos, nem tampouco fazer um comparativo de importância entre os dois já citados, mas sim, expor as beneficies que a Educação provê e que consequentemente caminha em consonância com outros fatores determinantes para o desenvolvimento de um Estado. Esta educação que fora considerada apenas um dos indicadores de desenvolvimento, hoje é considerada como um fator que impulsiona inovações, o avanço tecnológico em geral e é a variável que realmente faz a diferença nos países desenvolvidos.

Assim sendo, em Freire (1987, p. 15) encontra-se que "a educação tem caráter permanente", e disso entende-se que ela é uma herança que o sujeito dá a si mesmo, capital intangível de maior valor do homem, que é o seu conhecimento, a sua educação obtida. Mas, e quanto aqueles que não possuem acesso a esta educação? Geralmente, paralelo a isso, vem a falta de acesso a saneamento básico, alimentação e dignidade, sendo a miséria e a pobreza os únicos ativos desse ser humano, "[...] em uma economia onde a única certeza é a incerteza, a fonte certa de vantagem competitiva duradoura é o conhecimento" (TAKEUCHI; NONAKA, 2008, p. 39).

Acesso ao conhecimento é um processo necessário para sobrevivência, ora, aqui estabelece-se um paradoxo, onde quem não possui acesso a condições básicas não terá ânsia por conhecer e, consequentemente, não sairá da atual situação. Por outro lado, não há desenvolvimento se não houver conhecimento, portanto, é dever do ser humano que o possui utiliza-lo em favor da vida e da busca de caminhos para levar àqueles que não o possuem.

A literatura atual é muito clara quando afirma que o desenvolvimento de uma civilização perpassa por investimentos em educação. Não há na história humana casos de sucesso de países que se desenvolveram sem se alicerçar, também, em investimentos eloquentes em educação. Afirmar que ela é a única responsável pelo desenvolvimento nos países é assumir uma postura de extrema prepotência, afinal, é sabido que a renitente defasagem de saneamento básico confere estragos maiores do que os alcançados por um ataque terrorista (GREEN, 2009).

A prestação de serviços públicos decentes é uma 
das funções essenciais de um Estado efetivo, tanto para desenvolver uma economia dinâmica como para preservar sua legitimidade. Os investimentos sociais em saúde, educação, água limpa e saneamento não são um luxo para países que conseguiram crescer. (GREEN, 2009, p. 43)

Culturas que possuem povos que não têm acesso à educação, não produzirão grandes avanços tecnológicos (THUROW, 2001).

Se avanços tecnológicos e inovação só são possibilitados pelo acesso à educação, e que para que essa aconteça são necessárias condições apropriadas, é possível compreender que muita genialidade e talento se perde devido à falta de oportunidades de uma educação de qualidade, essa, que permite que o talento humano seja inventivo.

A educação é crucial para romper o ciclo da pobreza. Ela constitui um direito em si e prepara indivíduos para ter vidas plenas, compreender o mundo e, em última análise, desenvolver a autoconfiança necessária para se fazer ouvir. Uma educação de qualidade é emancipatória, um caminho para uma liberdade maior e uma gama mais ampla de opções, além de abrir portas para uma saúde melhor e mais oportunidades e bemestar material (GREEN, 2009, p. 45).

Em cima disso, é possível afirmar que se a Educação fosse acessível a todos, muitos problemas que perpassam a sociedade já poderiam estar resolvidos, dado que sem condições médias (e não mínimas) de subsistência já seria possível que a inventividade humana se colocasse a prova. Essa "condição mínima" de subsistir é diabólica, não há como sobreviver com USD 1,00 por dia, e ainda que isto fosse possível, ter um dólar, e não ter perspectiva de vida, saneamento básico, acesso à educação, a democracia e a ascensão social não resolveria o problema dessa pessoa,

[...] embora tenha havido progressos inegáveis em nossas capacidades tecnológicas desde Galileu e Newton, podemos questionar se nossa capacidade de nos governar inteligentemente atingiu qualquer plano mais elevado do que o encontrado na Idade Média (KOTLER, JATUSRIPITAK; MAESINCEE, 1997, p. 3).

A educação beneficia a construção de uma sociedade mais democrática, sendo considerada um instrumento essencial para modificar a disseminação de carências e dificuldades que se perpetuam de geração em geração, tendo em vista que o acesso ao conhecimento permite visão de futuro e embasa melhores escolhas, fortalecendo a superação da desigualdade pelas camadas menos favorecidas da população.

A questão do acesso a informações não é um debate abstrato; é uma ferramenta essencial da cidadania.

conhecimento amplia horizontes, permite que pessoas façam opções bem fundamentadas $e$ fortaleçam sua capacidade de exigir direitos. Garantir o acesso a conhecimentos e informações é absolutamente essencial para que pessoas em situação de pobreza superem as desigualdades em todo o mundo. Em âmbito nacional, a capacidade de absorver, adaptar e gerar conhecimentos e transformá-los em tecnologia determina, cada vez mais, as perspectivas de uma economia (GREEN, 2009, p. 56).

O primeiro elemento motor do desenvolvimento é o descontentamento com o 
estado atual e a ânsia por um estado desejado, em que a educação assume uma função insubstituível, seja como precursora de ferramentas estratégicas de ação ou na formação de pessoas que desejam estados desenvolvidos. Aristóteles inaugura seu livro número 1 da Metafísica afirmando que "todos os homens possuem, naturalmente, o desejo de conhecer". (FREIRE, 1987, p. 17). A educação é mais autêntica quanto mais desenvolve este ímpeto ontológico de criar. A educação deve ser desinibidora e não restritiva. É necessário darmos oportunidade para que os educandos possam ser eles mesmos.

Então, imbricando as afirmativas acima emerge a questão: em que momento da vida que essa ânsia pelo novo deixa de ser interessante? A partir do momento em que se priva o homem de seus direitos básicos instituídos na Declaração Universal dos Direitos Humanos (D.U.D.H.) ${ }^{3}$, que e em seu preâmbulo enuncia:

\begin{abstract}
Considerando que o reconhecimento da dignidade inerente a todos os membros da família humana e de seus direitos iguais e inalienáveis é o fundamento da liberdade, da justiça e da paz no mundo, considerando que o desprezo e o desrespeito pelos direitos humanos resultaram em atos bárbaros que ultrajaram a consciência da Humanidade e que o advento de um mundo em que todos gozem de liberdade de palavra, de crença e da liberdade de viverem a salvo do temor e da necessidade foi proclamado como a mais alta aspiração do homem comum (UNESCO, 2009, p. 2)
\end{abstract}

É factível que a falta de acesso à educação gera o desrespeito e o desprezo pelos direitos humanos que resultam em atos bárbaros que ultrajam a Humanidade. A falta de conhecimento é a ignorância, mas é necessário entender que esses atos são as vozes do advento de um mundo onde todos gozam de liberdade da palavra, os oprimidos clamam por condições mínimas de sobrevivência, e, na ausência de conhecimento, é da ignorância que fazem o uso.

A Declaração Universal dos Direitos Humanos contém trinta artigos, os quais, entre outros, preveem que: os seres humanos nascem livres, tem direito a vida, não serão submetidos a situações degradantes e desumanas, terão direito à propriedade, à liberdade e à segurança pessoal, etc., ora, a falta de condições básicas de subsistência mina a condição natural do ser humano que é a de conhecer, afinal, sua luta diária é pela sobrevivência e não pelo conhecimento.

Para discutir esse tema se faz necessário a resolução de um grande mal-entendido: escola e educação não são a mesma coisa. Educação se insere em um espectro muito mais amplo do que escola, "[...] ninguém escapa da educação" (BRANDÃO, 2007, p. 7). Já da escola sabemos que muita gente tenta escapar, mas da educação é impossível "[...] em casa, na rua, na igreja ou na escola [...] todos nós envolvemos pedaços da vida com ela: para aprender, para ensinar, para aprender-e-ensinar" (BRANDÃO, 2007, p. 7).

Da escola formal muitos conseguem fugir, mas não da escola da vida, essa pode ser mais confundida com educação. A escola enquanto instituição formal tal como conhecemos não é algo tão antigo, foi criada durante a era Vitoriana, e, quanto a sua expansão global:

Imagine tentar comandar o show, tentar comandar o planeta inteiro, sem computadores, sem telefones, com informações escritas à mão em papel, e viajando em navios. Mas os Vitorianos realmente 0 fizeram. $\mathrm{O}$ que eles fizeram foi incrível. Eles criaram um computador global feito de pessoas. Ele ainda está conosco hoje. É a chamada máquina administrativa burocrática. Para que essa máquina siga funcionando, você precisa de muitas e muitas pessoas. Eles fizeram outra máquina para produzir essas pessoas: a escola. As escolas produziriam as

\footnotetext{
${ }^{3}$ Adotada e proclamada pela resolução 217 A (III) da Assembleia
} Geral das Nações Unidas em 10 de dezembro de 1948 
pessoas que depois se tornariam parte da máquina administrativa burocrática. Elas devem ser idênticas umas às outras. E devem saber três coisas: devem ter uma boa caligrafia, pois a informação é escrita à mão; devem saber ler; e devem ser capazes de fazer

multiplicação, divisão, adição e subtração de cabeça. Devem ser idênticas ao ponto de você poder selecionar uma da Nova Zelândia e enviá-la ao Canadá, onde ela seria imediatamente funcional. (MITRA, 2013).

Que grande invenção, não? Tão grandiosa que perdura até hoje, da mesmíssima maneira tal qual foi concebida a pouco mais de 300 anos. Essa é a escola, depositando envelopes de informação nos alunos ${ }^{4}$. Essa é a escola que muitos afirmam estar quebrada e falida, mas a realidade é o oposto, ela está incrivelmente estruturada, porém, obsoleta.

Assim como vimos com o ato de gerir, educação é intrínseco ao homem, “[...] implica uma busca realizada por um sujeito que é o homem. O homem deve ser sujeito de sua própria educação" (FREIRE, 1996, p. 14), ela ocorre transversalmente na vida homem. "Não há uma forma única nem um único modelo de educação; a escola não é o único lugar onde ela acontece e talvez nem seja o melhor; o ensino escolar não é a sua única prática e o professor profissional não é o seu único praticante" (BRANDÃO, 2007, p. 9)

Diferente da escola, a educação parte da complexidade e da incompletude do sujeito, ela exige uma reflexão acerca do próprio homem, e ele "[...] se sabe inacabado, por isso se educa" (FREIRE, 1994, p. 14). A educação consiste em uma procura constante do homem em busca de si mesmo, por isso "[...] ninguém educa ninguém [...]" (FREIRE, 1996, p. 14), o professor, os pais, os ambientes aos quais nos expomos compõem esse todo que chamamos de educação.

A educação consiste em reconhecer os diferentes saberes, e é importante frisar que "[...] a sabedoria parte da ignorância. Não há ignorantes absolutos" (FREIRE, 1987, p. 14). Ao conversar com alguém "menos instruído" faz-se fundamental reconhecer que o que lhe falta é um saber sistematizado, e não configura-lo como um ignorante.

Em consonância a esse reconhecimento da origem da sabedoria, o filósofo francês Edgar Morin afirma que todo conhecimento comporta o risco do erro e da ilusão e "[...] a educação deve mostrar que não há conhecimento que não esteja, em algum grau, ameaçado pelo erro e pela ilusão" (MORIN, 2000, p. 19). À educação cabe o papel de libertar o sujeito dos erros, ilusões e cegueiras providas pelo conhecimento desenvolvido pela humanidade.

E o que isso quer dizer? A educação deve prover meios para que nos tornemos capazes de suspender juízos e corrigir eventuais ilusões providas pelo que nos foi apresentado, afinal, "[...] o conhecimento, sob forma de palavra, de ideia, de teoria, é o fruto de uma tradução/reconstrução por meio da linguagem e do pensamento e, por conseguinte, está sujeito ao erro" (MORIN, 2000, p. 20).

Ainda não está claro? Vamos a uma situação prática: quantas vezes você não conseguiu colocar no papel o que estava em sua mente? Ou quantas vezes teve uma ideia brilhante e ninguém lhe entendeu e você responde "pois é, mas é porque não estou conseguindo explicar direito o que desejo"? É isso, a educação deve nos prover meios para que possamos nos expressar melhor.

E assim, continuamos na perspectiva de Paulo Freire (1996) em que seu pensamento pode ser resumido na frase: a educação ensina o aluno a ler o mundo, ela é resiliência, é cotidiano, é a cultura, enfim, é uma trama complexa que se desenvolve no ambiente ao qual estamos inseridos, esse entorno é conhecido por ecologia cognitiva, que são "[...] ambientes propiciadores de experiências de conhecimento" (ASSMANN, 2012, p. 22).

Em consonância a esse discurso encontramos em Pozo (2002, p. 25): Graças à aprendizagem
incorporamos a cultura,
que por sua vez traz
incorporadas novas
formas de aprendizagem.
Seguindo a máxima de
Vygotsky (1978), segundo
a qual todas as funções
psicológicas superiores são

\footnotetext{
${ }^{4}$ Educação bancária, termo cunhado por Paulo Freire. Veremos mais a respeito do autor mais à frente.
} 
geradas na cultura, nossa aprendizagem responde não só a um desenho genético, mas principalmente a um desenho cultural. Cada sociedade, cada cultura gera suas próprias formas de aprendizagem, sua cultura da aprendizagem. Desse modo, a aprendizagem da cultura acaba por levar a uma determinada cultura da aprendizagem.

A educação ocorre por meio da cultura? O correto também é verdadeiro? Ou ainda, seria a educação um fenômeno de cultura? Ou a cultura um fenômeno de educação? "A cultura e a aprendizagem são elementos interpenetrantes, na qual a cultura vai influenciar no modo como aprenderemos $[. .$.$] ", tanto quanto "[...] o modo$ como aprendemos vai influenciar em nossa cultura" (ALMEIDA; FERNANDES JÚNIOR, 2014, p. 84). Importante salientar que é apenas quando

Um povo alcança um
estágio complexo de
organização da sua
sociedade e de sua
cultura; quando ele
enfrenta, por exemplo, a
questão da divisão social
do trabalho e, portanto,
do poder, é que ele
começa a viver e a pensar
como problema as formas
e os processos de
transmissão do saber
(BRANDÃO, 2007, p. 16,
grifos do autor).

Entendamos o vocábulo "problema" não como algo ruim que aconteça ou uma dificuldade a ser resolvida, mas como um complexo problemático, um "problema bom", como o fato de duas coisas boas para escolher, mas poder escolher somente uma. No caso da citação de Brandão, o ato de entender a importância dos processos educacionais e da transmissão da cultura é uma forma de perpetuação da espécie, afinal, “[...] o homem não é uma ilha. É comunicação. Logo, há uma estreita relação entre comunhão e busca" (FREIRE, 1996, p. 14).

Em Freire (1987, p. 14) encontramos ainda “[...] a educação tem caráter permanente. Não há seres educados e não educados. Estamos todos nos educando [...]", isso tem muito a ver também com as afirmações que o autor faz em relação a humildade do professor para com seus alunos: reconhecer os diferentes saberes que cada um possui e saber lidar com isso.

Essa recomendação de Paulo Freire faz muito sentido contemporaneamente, pois nessa atual conjuntura que nos envolve, 0 acesso a informação é muito grande. Em uma sala de aula um aluno pode contrapor um argumento do professor após uma busca na internet, e, nesse caso, se o professor realmente estiver errado, deve assumir uma postura humilde e reconhecer o erro. Além disso, reconhecer o que o aluno já traz de conhecimento, suas convicções, suas experiências, demonstra profundo respeito por parte do professor.

Quando falamos em ética e valores, pode-se pensar em começar com gestos simples, pequenos detalhes, mas que no dia a dia ganham corpo e podem se tornar um modelo de vida para aqueles que sentem-se distantes de fazer parte da sociedade do conhecimento.

\section{CONSIDERAÇÕES FINAIS}

A relevância, mesmo que tardia dada à educação no que tange ao desenvolvimento de um país, tem relação total (e não podia ser diferente) com a atual conjuntura sobre a qual se debruça a sociedade, em que o conhecimento é a maior riqueza de uma Nação. A maior promotora de conhecimento em uma sociedade é a Educação, e, portanto, faz-se necessário dar relevância a esta, de modo a estuda-la separada de outros indicadores na tentativa de entender, de fato, sua importância no desenvolvimento de um Estado, em que cada ser possui um talento, mas para que haja inovação são necessárias condições apropriadas, de modo que se impacte positivamente a sociedade por meio da inovação.

Ao proclamar que "Educação é tudo" não se deve ater a afirmação apenas como um discurso moral, legal ou social. Isso ocorre, pois, a Educação é o cimento da sociedade do conhecimento que se pretende construir. $O$ termo em letra maiúscula refere-se a uma instituição, e não apenas ao simples fato de ir à escola para obter um diploma, mas todo um escopo. Não devemos limitar a educação ao ensino ministrado por uma forma sistematizada, que podemos identificar com a transmissão socialmente organizada de estabelecer cultura, contudo deve-se considerar a formação adquirida 
por reflexão própria sobre os dados apreendidos na e pela experiência.

A relevância da educação no que tange ao consumo (em que mais pessoas vão estudar se tiverem melhores condições econômicas) e ao investimento (em que é necessária mão de obra qualificada para manter o funcionamento das modernas indústrias), são de ordem econômica e já são alvo de estudos, porém, o desafio ainda consiste nos aspectos sociológicos e de ordem pedagógica da educação.

\section{REFERÊNCIAS}

ALMEIDA, S. C. D.; FERNANDES JÚNIOR, A. M. Ambientes de aprendizagem em Ead. Maringá: Cesumar, 2014.

ASSMANN, H. Reencantar a educação: rumo a sociedade aprendente. 12. ed. Petrópolis, RJ: Vozes, 2012.

BACON, F. Novum organum ou verdadeiras indicações acerca da interpretação da natureza. São Paulo: Nova Cultural, 1999.

BAUMAN, Z.; BORDONI, C. Estado de Crise. Rio de Janeiro: Zahar, 2016.

BAUMAN, Z. Modernidade Líquida. Rio de Janeiro: Zahar, 2001.

BAUMAN, Z. A ética é possivel num mundo de consumidores?. Rio de Janeiro: Zahar, 2011.

BETINI, G. A. Escola e educação, a quem interessa? Argumentos Pró-Educação, Pouso Alegre, v. 2, n. 4, p. 279-300, mai./ago., 2017. Disponível em: http://ojs.univas.edu.br/index.php?journal=argu mentosproeducacao\&page=article\&op=view\&pat h[]=185. Acesso em: 28 mai. 2018.

BOFF, L. Ethos Mundial: Um consenso mínimo entre os humanos. Rio de Janeiro: Sextante, 2003.

BRANDÃO, C. R. O que é educação. São Paulo: Brasiliense, 2007.

CAPRA, F. O Ponto de mutação. São Paulo: Cultrix, 2006.
CASTELLS, M. A sociedade em rede. São Paulo: Paz e Terra, 1999.

DE MASI, D. O futuro chegou: modelos de vida para uma sociedade desorientada. Rio de Janeiro: Casa da Palavra, 2014.

DUSSEL, E. Ética da Libertação: na idade da globalização e da exclusão. Petrópolis, RJ: Vozes, 2000.

FREIRE, P. Educação e mudança. Rio de Janeiro: Paz e Terra, 1994.

FREIRE, P. Pedagogia do oprimido. 17. ed. Rio de Janeiro: Paz e Terra, 1987.

FREIRE, P. Pedagogia da autonomia. 38. ed. São Paulo: Paz e Terra, 1996.

GREEN, D. Da pobreza ao poder: Como cidadãos ativos e estados efetivos podem mudar o mundo. São Paulo: Cortez. Oxford: Oxfam International, 2009.

HARARI, Y. N. Homo Deus: uma breve história do amanhã. São Paulo: Companhia das Letras, 2016.

KOTLER, P; JATUSRIPITAK, S.; MAESINCEE, S.. O marketing das nações: uma abordagem estratégica para construir as riquezas nacionais. São Paulo: Futura, 1997.

LELYVELD, J. Great soul: Mahatma Gandhi and his struggle with India. New York: Alfred A. Knopf, 2011.

LÉVY, P. A inteligência coletiva: por uma antropologia do ciberespaço. 4. ed. São Paulo: Loyola, 2003.

MITRA, S. Construa uma escola na nuvem. TED 2013, 2013. Disponível em: https://www.ted.com/talks/sugata mitra build a school in the cloud?language=pt. Acesso em: 28 mai. 2018.

MORIN, E. Os sete saberes necessários à educação do futuro. [versão eletrônica]. São Paulo, Brasília: Cortez, UNESCO, 2000.

POZO, J. I. Aprendizes e mestres: a nova cultura da aprendizagem. Porto Alegre: Artmed, 2002. 
TAKEUCHI, H.; NONAKA, I. Criação e Dialética do Conhecimento. In: TAKEUCHI, H.; NONAKA, I. Gestão do Conhecimento. Porto Alegre: Artmed, 2008. Cap. 1, p. 17-38.

TUROW, L. C. A construção da riqueza: as novas regras para indivíduos, empresas e Nações Numa Economia Baseada no Conhecimento. São Paulo: Rocco, 2001.

UNESCO. Declaração Universal dos Direitos Humanos. 2009. Disponível em: http://www.onu.org.br/img/2014/09/DUDH.pdf Acesso em: 28 mai. 2018.

VENDEMIATI, A. Em primeira pessoa: elementos de ética geral. Sarandi: Humanitas Vivens, 2008. 